\title{
06.1
}

\section{Гетероструктурные AgCl/BN-наноматериалы с высокой сорбционной способностью и фотокаталитической активностью}

\author{
() А.С. Конопацкий, Д.В. Попова, В.В. Калинина, Д.В. Лейбо, А.Т. Матвеев, Д.В. Штанский \\ Национальный исследовательский технологический университет „МИСиС“, Москва, Россия \\ E-mail: konopatskiy@misis.ru
}

Поступило в Редакцию 7 апреля 2021 г.

В окончательной редакции 3 июня 2021 г.

Принято к публикации 2 июля 2021 г.

\begin{abstract}
Изучены фотокаталитическая активность и сорбционная способность микронных порошков $h$-BN и гетерогенных структур $\mathrm{AgCl} / h$-BN, полученных полиольным методом. Химический и фазовый состав, а также микроструктура поверхности изучены методами сканирующей электронной микроскопии, энергодисперсионной спектроскопии, рентгенофазового анализа и рентгеновской фотоэлектронной спектроскопии. Продемонстрированы высокая фотокаталитическая активность и сорбционная способность гетерогенных структур $\mathrm{AgCl} / \mathrm{BN}$ в реакции разложения органического красителя метиленового синего под ультрафиолетовым облучением.
\end{abstract}

Ключевые слова: гетерогенные материалы, фотокатализ, гексагональный нитрид бора, хлорид серебра.

DOI: $10.21883 /$ PJTF.2021.19.51515.18813

Загрязнение природных вод тяжелыми металлами, промышленными красителями и различными органическими соединениями является одной из наиболее острых экологических проблем современности [1]. В свою очередь это ведет к пагубным последствиям для здоровья человека: развитию неврологических, сердечнососудистых и кишечных заболеваний [2]. В связи с этим актуальной научной задачей является поиск новых эффективных фотокаталитических систем для очистки сточных вод. При разработке новых фотокатализаторов удобно использовать сравнительно простой, но в то же время имеющий большую практическую значимость процесс разложения органических красителей в водных растворах. Гетерогенные структуры, состоящие из соединений переходных металлов и новых типов двумерных подложек, таких как графен, дисульфид молибдена, максены (MXenes) и гексагональный нитрид бора, привлекают в последние годы все большее внимание $[3,4]$. Нанокомпозит, состоящий из $\mathrm{TiO}_{2}$ и графена/оксида графена, показывает выраженные фотокаталитические свойства за счет высокой пористости и соответственно возросшей сорбционной способности материала [5]. Показано, что система $\mathrm{MoS}_{2} / \mathrm{ZnO}$ является перспективным фотокатализатором для очистки водных растворов от органических красителей и тяжелых металлов за счет более эффективного разделения зарядов на границах раздела оксид цинка-дисульфид молибдена [6]. Большой интерес в качестве перспективной подложки для каталитически активных частиц вызывает гексагональный нитрид бора $(h$-BN) [7]. Показано, что гетерогенный композит $h$ - $\mathrm{BN} / \mathrm{TiO}_{2}$, в котором $\mathrm{TiO}_{2}$ является носителем частиц $h$-BN, проявляет выраженные фотокаталитические свойства [8]. Установлено, что небольшие добавки $h$-BN повышают стабильность и фотокаталитическую активность $\mathrm{AgBr}$ и $\mathrm{AgI}$ в реакции разложения органических красителей [9]. Это позволяет предположить, что другие соединения серебра, в частности $\mathrm{AgCl}$, могут являться перспективными компонентами в фотокаталитической системе на основе $h$-BN. Таким образом, целью настоящей работы является установление влияния наночастиц $\mathrm{AgCl}$ на поверхности $h$ - $\mathrm{BN}$ на фотокаталитические свойства материала. В рамках работы были синтезированы гетерогенные материалы $\mathrm{AgCl} / \mathrm{BN}$, изучены их структура и фотокаталитическая активность разложения красителя метиленового синего (МВ) в водном растворе под воздействием ультрафиолетового (УФ) облучения.

Для получения гетерогенных структур $\mathrm{AgCl} / \mathrm{BN}$ был использован модифицированный полиольный синтез [10]. Для этого $100 \mathrm{mg}$ микронного порошка $h$-BN диспергировали в $50 \mathrm{ml}$ полиэтиленгликоля (ПЭГ-400) путем ультразвуковой обработки с погружным сонотродом в течение $3 \mathrm{~min}$. В суспензии растворяли $75 \mathrm{mg}$ $\mathrm{AgNO}_{3}$ и полученную смесь обрабатывали УФ-излучением $(\lambda=185 \mathrm{~nm})$. По окончании синтеза в среду добавляли $7 \mathrm{ml} 0.01 \mathrm{M}$ раствора $\mathrm{HCl}$. Итоговый порошок получали после промывки в дистиллированной воде с использованием центрифугирования и просушивания осадка в потоке воздуха.

Изучение структуры и состава полученных материалов проводилось методом сканирующей электронной микроскопии (СЭМ) и энергодисперсионной спектроскопии (ЭДС) (JEOL 7600F). Фазовый состав исследовался методом рентгеновского фазового анализа (РФА) (D2-Phaser, „Bruker"). Химическое состояние поверхности изучалось методом рентгеновской фотоэлектронной спектроскопии (РФС) (PHI5500VersaProbeII). Калибровка спектров проводилась по линии С $1 s(285.0 \mathrm{eV})$.

Фотокаталитическая активность изучалась как для $\mathrm{AgCl} / \mathrm{BN}$, так и для чистого $h$-BN и $\mathrm{AgCl}$. Для этого $50 \mathrm{mg}$ фотокатализатора добавляли в $100 \mathrm{ml}$ раствора 
$a$

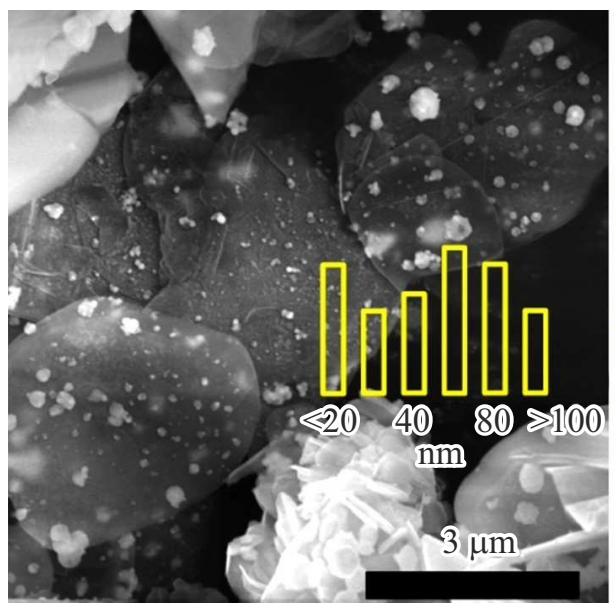

$b$

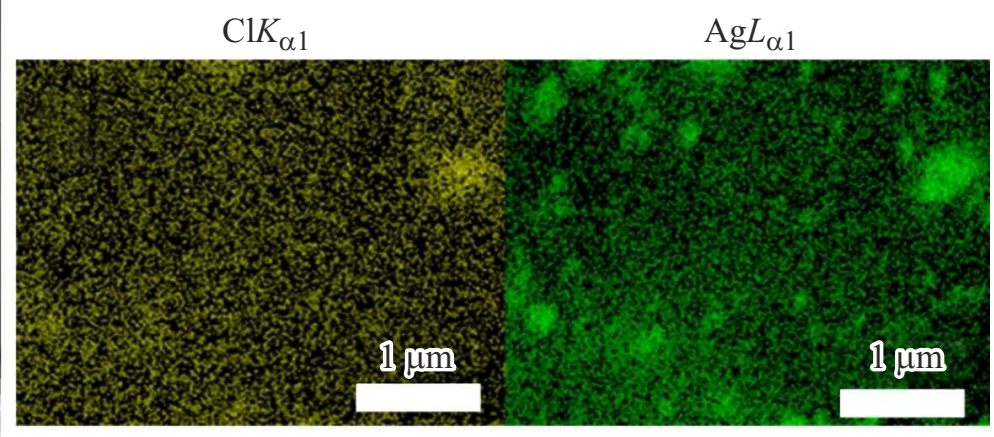

Pис. 1. Электронно-микроскопическое изображение $(a)$ и карты распределения элементов $(b)$ гетерогенных структур $\mathrm{AgCl} / \mathrm{BN}$.

MB с концентрацией $4 \mathrm{mg} / 1$ и проводили диспергирование с помощью ультразвуковой обработки. Полученную систему в условиях постоянного перемешивания оставляли на магнитной мешалке в темноте на $120 \mathrm{~min}$ для установления сорбционно-десорбционного равновесия. Затем изучаемую систему обрабатывали УФ-облучением в течение $90 \mathrm{~min}$. В качестве источника УФ-излучения использовали $U$-образную лампу длиной $190 \mathrm{~mm}$ и диаметром $19 \mathrm{~mm}$. Мощность лампы составляла $145 \mathrm{~W}$, мощность УФ-излучения - $50 \mathrm{~W}$; кварцевый стакан с изучаемым раствором располагался на расстоянии $10 \mathrm{~cm}$ от лампы. После УФ-обработки суспензию осаждали, используя центрифугу, и раствор (без осадка) использовали в качестве образца для спектрофотометрических исследований на оптическом спектрометре (UV-VIS-NIR „Cary-5000“, Variant). Для изучения сорбционной способности полученных материалов использовалась та же методика, но без применения УФ-облучения. По величине интенсивности поглощения (оптической плотности) судили об изменении концентрации красителя в растворе.

На рис. 1 представлены результаты СЭМ- и ЭДСанализа полученных гетерогенных структур $\mathrm{AgCl} / \mathrm{BN}$.

Значительная доля частиц $\mathrm{AgCl}$ (около 90\%) имеет размер менее $100 \mathrm{~nm}$, однако отдельные частицы достигают размера $300 \mathrm{~nm}$ (рис. 1,a). Карты распределения элементов $\mathrm{Ag}$ и $\mathrm{Cl}$ (рис. $1, b)$ подтверждают формирование хлорида серебра. По результатам анализа методом ЭДС был установлен химический состав $\mathrm{AgCl} / \mathrm{BN}$ : B 51.1 at.\%, $\mathrm{N}-45.1$ at.\%, $\mathrm{O}-2.4$ at.\%, $\mathrm{Ag}-2.4$ at.\%, $\mathrm{Cl}-0.4$ at.\%. Массовая доля $\mathrm{AgCl}$ в гетерогенном материале составляет порядка $8.5 \%$. Частицы исходного порошка $h$-BN имеют форму пластин, толщина которых варьируется от 200 до $600 \mathrm{~nm}$. Следует отметить, что в ЭДС-спектре материала присутствует небольшое количество кислорода, что указывает на формирование оксинитрида BNO на поверхности исходных пластин $h$-BN, при этом как до, так и после синтеза бор и азот находятся в эквиатомном соотношении: В - 50.5 at.\%, $\mathrm{N}-45.4$ at.\%, O - 4.1 at.\%.

Результаты РФА, а также данные о химическом состоянии поверхности приведены на рис. 2.

Согласно полученным дифрактограммам, порошок $h$-BN в исходном состоянии представлен только фазой гексагонального нитрида бора, отличающейся высокой степенью кристалличности, без примесей оксида $\mathrm{B}_{2} \mathrm{O}_{3}$. В результате синтеза на поверхности $h$-BN сформировались наночастицы $\mathrm{AgCl}$; соответствующие дифракционные рефлексы обозначены на рентгенограмме образца $\mathrm{AgCl} / \mathrm{BN}$. Слабый сигнал, наблюдаемый при $2 \theta=38.1^{\circ}$, соответствует линии (111) металлического серебра. Можно предположить, что металлическое серебро образуется на поверхности частиц $\mathrm{AgCl}$ в результате их частичной деградации на свету или в результате неполной реакции серебра с соляной кислотой.

На РФС-спектрах высокого разрешения (рис. 2,b) наблюдаются сигналы при значениях энергии связи 367.9 и $374 \mathrm{eV}$, что соответствует пикам $\mathrm{Ag} 3 d_{5 / 2}$ и $\mathrm{Ag} 3 d_{3 / 2}$. При аппроксимации этих пиков можно выделить следующие компоненты: $\mathrm{Ag}^{+}$(367.8 и $\left.373.8 \mathrm{eV}\right)$, что подтверждает формирование хлорида серебра [11], a также $\mathrm{Ag}^{0}(368.4$ и $374.6 \mathrm{eV})$ с гораздо меньшей интенсивностью, что хорошо согласуется с результатами РФА. Наличие третьего пика в спектрах при больших величинах энергии связи (396.5 и $375.7 \mathrm{eV}$ ) вызвано зарядкой образца в ходе эксперимента. В спектре хлора также можно выделить два пика: $\mathrm{Cl} 2 p_{3 / 2}(197.0 \mathrm{eV})$ и $\mathrm{Cl} 2 p_{1 / 2}(198.7 \mathrm{eV})$. Также по результатам РФС был определен элементный анализ поверхности материала: $\mathrm{C}-23.5$ at.\%, $\mathrm{N}$ - 34.4 at.\%, B - 32.2 at.\%, O 7.9 at.\%, $\mathrm{Ag}-1.0$ at.\%, $\mathrm{Cl}-1.0$ at.\%, что хорошо согласуется с результатами ЭДС.

На рис. 3 показано изменение интенсивности поглощения МВ в ходе фотокаталитических испытаний. 

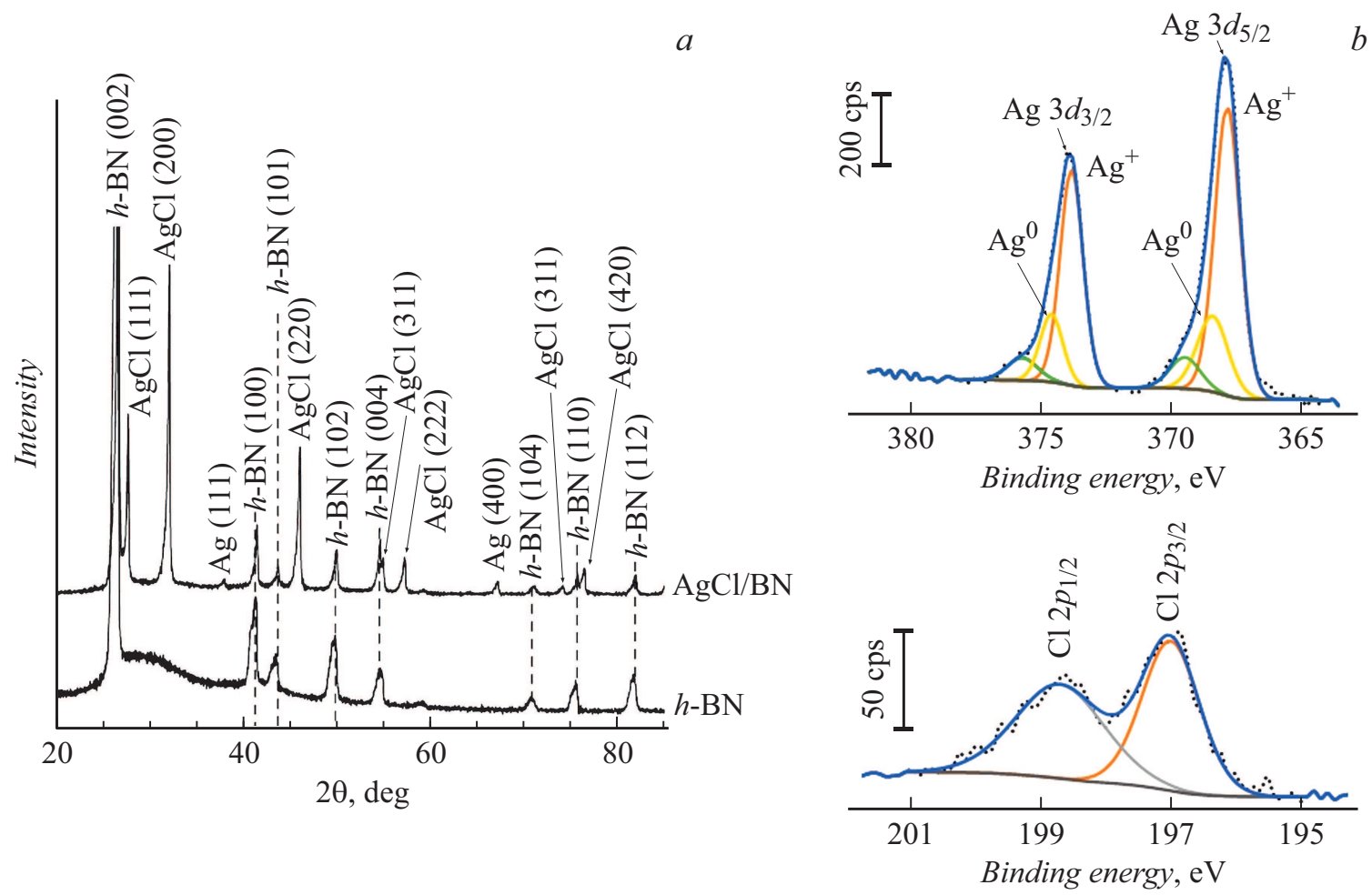

Рис. 2. Рентгеновские $(a)$ и РФС-спектры $(b)$ гетерогенных структур $\mathrm{AgCl} / \mathrm{BN}$ и исходного порошка $h$-BN.

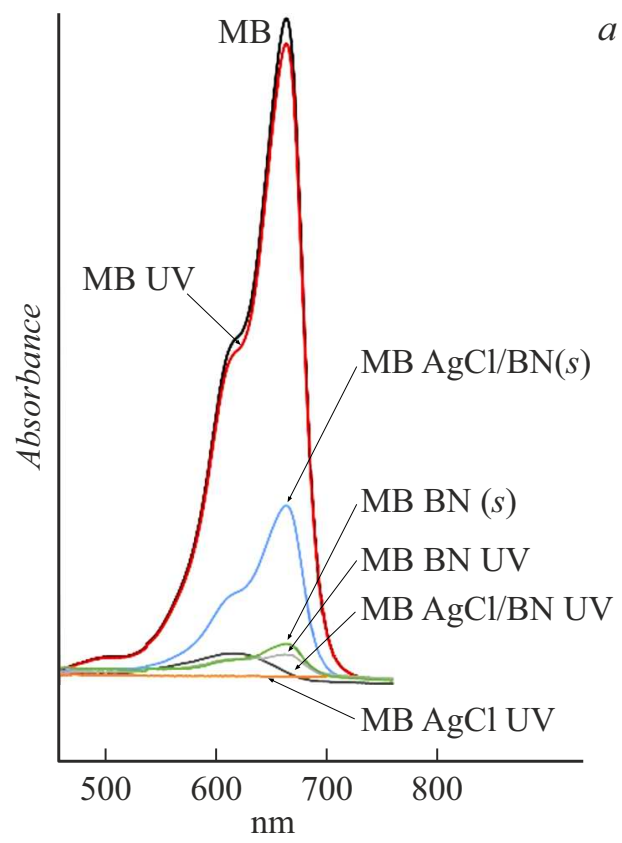

$a$

$b$

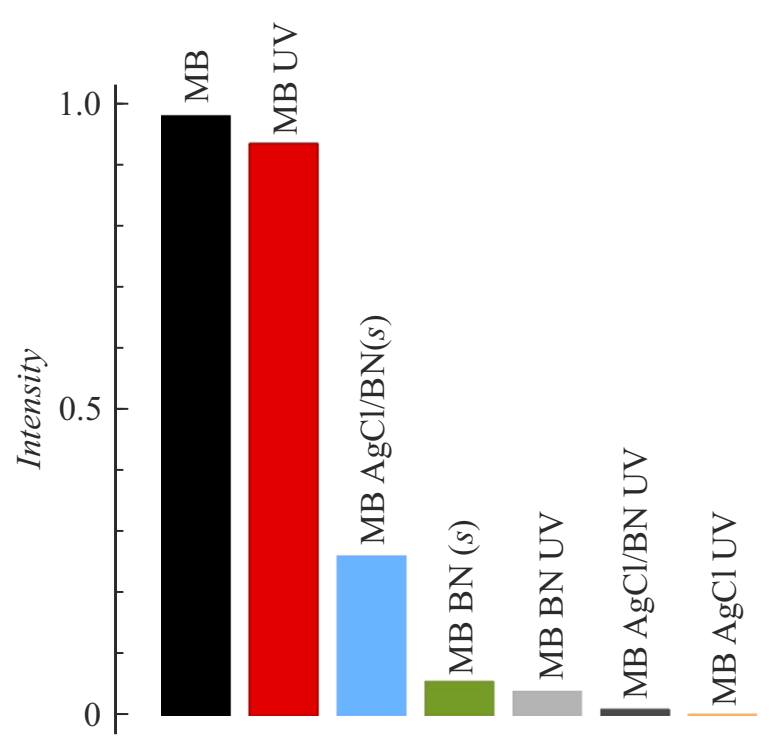

Рис. 3. Спектры поглощения MB $(a)$ и сравнение интенсивностей поглощения образцов $(b)$. МВ - исходный раствор МВ; MB UV - раствор MB после УФ-облучения; MB BN $(s)$ - после выдержки в МВ исходного порошка $h$ - $\mathrm{BN} ; \mathrm{MB} \mathrm{AgCl} / \mathrm{BN}(s)-$ после выдержки в МB гетерогенных структур $\mathrm{AgCl} / \mathrm{BN}$; MB BN UV - после фотокаталитических испытаний с $h$-BN; MB AgCl/BN UV - после фотокаталитических испытаний с $\mathrm{AgCl} / \mathrm{BN}$; $\mathrm{MB} \mathrm{AgCl} \mathrm{UV}$ - после фотокаталитических испытаний c $\mathrm{AgCl}$. 
Исходная интенсивность красителя (MB) была принята за единицу.

Максимум интенсивности поглощения МВ можно наблюдать на длине волны $668 \mathrm{~nm}$ (рис. 3,a). Под воздействием УФ-облучения оптическая плотность исходного раствора красителя незначительно падает (не более чем на 5\%), что связано с частичным его разложением. Значительное снижение концентрации красителя в растворе наблюдается после выдержки в нем как чистого нитрида бора (образец $\mathrm{MB} \mathrm{BN}(s)$ ), так и гетерогенных структур $(\mathrm{MB} \mathrm{AgCl} / \mathrm{BN}(s))$. Величина оптической плотности снижается до $27 \%$ для $\mathrm{MB} \mathrm{AgCl} / \mathrm{BN}(s)$ и составляет менее $10 \%$ для $\mathrm{MB} \mathrm{BN}(s)$ (рис. $3, b)$. Наблюдаемая разница в снижении оптической плотности образцов объясняется тем, что $\mathrm{AgCl}$ обладает меньшей сорбционной способностью в отношении МВ по сравнению с порошком $h$-BN. Наночастицы $\mathrm{AgCl}$ расположены на поверхности носителя и занимают значительную ее долю, тем самым ограничивая сорбционную способность $h$-BN. Значительная сорбционная способность в отношении $\mathrm{MB}$, являющегося катионным красителем, может быть объяснена наличием на поверхности $h$-BN отрицательного заряда [12]. Высокая адсорбция может быть также объяснена циклической ароматической структурой МВ, усиливающей $\pi$-стэкинг-взаимодействие с $h$-BN. Тем не менее в результате фотокаталитических испытаний исходного $h$-BN не наблюдалось заметного дополнительного снижения оптической плотности раствора (образец MB BN UV). Это указывает на слабую фотокаталитическую активность материала, объясняемую его широкой запрещенной зоной $E_{g}$, величина которой, по данным оптической спектроскопии, составила $5.7 \mathrm{eV}$. Для $\mathrm{AgCl} / \mathrm{BN}$ $E_{g}$ уменьшилась и составила $5.4 \mathrm{eV}$, что указывает на химическое взаимодействие $\mathrm{AgCl}$ c $\mathrm{BN}$. Величина оптической плотности МВ для этого образца близка к нулю, что свидетельствует о его высокой фотокаталитической активности. Образец, состоящий только из частиц $\mathrm{AgCl}$, показал полное разложение красителя, однако следует отметить, что содержание $\mathrm{AgCl}$ в этом образце примерно в 10 раз выше, чем в образце $\mathrm{AgCl} / \mathrm{BN}$. Это подчеркивает эффективность $h$-ВN в качестве активной подложки, повышающей фотокаталитическую активность $\mathrm{AgCl}$. В настоящее время механизм влияния $h$ - $\mathrm{BN}$ на фотокаталитическую активность изучен недостаточно, однако можно предположить, что в результате химического взаимодействия $\mathrm{AgCl}$ и $\mathrm{BN}$ снижается скорость рекомбинации носителей заряда, генерируемых в ходе фотокатализа. Таким образом, можно сделать вывод, что гетерогенные материалы на основе $h$-BN являются новыми перспективными фотокатализаторами.

\section{Финансирование работы}

Работа выполнена при финансовой поддержке Российского научного фонда (соглашение № 20-79-10286).

\section{Конфликт интересов}

Авторы заявляют, что у них нет конфликта интересов.

\section{Список литературы}

[1] K. Ahmad, H.R. Ghatak, S.M. Ahuja, Technol. Innov., 19, 100893 (2020). DOI: 10.1016/j.eti.2020.100893

[2] P.J. Landrigan, J.J. Stegeman, L.E. Fleming, D. Allemand, D.M. Anderson, L.C. Backer, F. Brucker-Davis, N. Chevalier, L. Corra, D. Czerucka, M.Y.D. Bottein, B. Demeneix, M. Depledge, D.D. Deheyn, C.J. Dorman, P. Fénichel, S. Fisher, F. Gaill, F. Galgani, W.H. Gaze, L. Giuliano, P. Grandjean, M.E. Hahn, A. Hamdoun, P. Hess, B. Judson, A. Laborde, J. McGlade, J. Mu, A. Mustapha, M. Neira, R.T. Noble, M.L. Pedrotti, C. Reddy, J. Rocklöv, U.M. Scharler, H. Shanmugam, G. Taghian, J.A.J.M. Van De Water, L. Vezzulli, P. Weihe, A. Zeka, H. Raps, P. Rampal, Ann. Glob. Heal., 86, 151 (2020). DOI: 10.5334/aogh.2831

[3] X. Feng, Z. Yu, Y. Sun, R. Long, M. Shan, X. Li, Y. Liu, J. Liu, Ceram. Int., 47, 7321 (2021). DOI: $10.1016 /$ j.ceramint.2020.11.151

[4] S. Hao, X. Zhao, Q. Cheng, Y. Xing, W. Ma, X. Wang, G. Zhao, X. Xu, Front. Chem., 8, 582146 (2020). DOI: $10.3389 /$ fchem. 2020.582146

[5] X. Zhou, X. Zhang, Y. Wang, Z. Wu, Front. Energy Res., 8, 1 (2021). DOI: $10.3389 /$ fenrg.2020.612512

[6] R. Gang, L. Xu, Y. Xia, J. Cai, L. Zhang, S. Wang, R. Li, J. Colloid Interface Sci., 579, 853 (2020). DOI: $10.1016 /$ j.jcis.2020.06.116

[7] A.M. Kovalskii, A.T. Matveev, Z.I. Popov, I.N. Volkov, E.V. Sukhanova, A.A. Lytkina, A.B. Yaroslavtsev, A.S. Konopatsky, D.V. Leybo, A.V. Bondarev, I.V. Shchetinin, K.L. Firestein, D.V. Shtansky, D.V. Golberg, Chem. Eng. J., 395, 125109 (2020). DOI: 10.1016/j.cej.2020.125109

[8] Q. Li, X. Hou, Z. Fang, T. Yang, J. Chen, X. Cui, T. Liang, J. Shi, Sci. China Mater., 63, 276 (2020). DOI: $10.1007 / \mathrm{s} 40843-019-1180-8$.

[9] W. Wu, X. Lv, J. Wang, J. Xie, J. Colloid Interface Sci., 496, 434 (2017). DOI: 10.1016/j.jcis.2017.02.046

[10] A.S. Konopatsky, D.V. Leybo, K.L. Firestein, Z.I. Popov, A.V. Bondarev, A.M. Manakhov, E.S. Permyakova, D.V. Shtansky, D.V. Golberg, J. Catal., 368, 217 (2018). DOI: $10.1016 /$ j.jcat.2018.10.016

[11] Y. Fan, Y. Bao, Z. Song, Z. Sun, D. Wang, D. Han, L. Niu, RSC Adv., 8, 24812 (2018). DOI: 10.1039/c8ra04180f

[12] T. Tarhan, Turkish J. Chem., 44, 1471 (2020). DOI: $10.3906 / \mathrm{kim}-2004-23$ 